\title{
Percutaneous Repair for the Treatment of Rupture of the Achilles Tendon: A Study of 20 Cases
}

\author{
Gautam D Salunkhe
}

\begin{abstract}
Background: Despite many techniques used for repair of the ruptured Achilles tendon, uncertainty of healing of the surgical wound remains a problem. This mainly determines the success of the surgery. The long-term results generally result in healing of the rupture, but poor healing of the wound occurs repeatedly. This causes apprehension in advising surgery over a conservative approach.
\end{abstract}

Objectives: To study the outcome of 20 cases of acute rupture of the Achilles tendon treated by the percutaneous technique.

Materials and methods: From March 2004 to March 2012, 20 cases of acute Achilles tendon rupture were treated by percutaneous repair by the method of $\mathrm{Ma}$ and Griffith. Modifications were used in distal end and delayed repairs. Immobilization was used after surgery. Postoperative complications were observed, and results assessed using the Leppilahti score after 6 months. Follow-up was done for 2 years.

Results: Percutaneous repair had significantly good results in $95 \%$ cases. There were two cases of sural nerve hypoesthesia, which was a minor problem and in no way hampered the longterm result. There were no re-ruptures. Patient satisfaction was high in terms of final result and cosmesis.

Conclusion: Percutaneous repair is a safe and reliable method for repair of the Achilles tendon rupture. It has a minor complication rate, and is advisable over open surgery.

Keywords: Achilles tendon rupture, Percutaneous repair, Wound healing.

How to cite this article: Salunkhe GD. Percutaneous Repair for the Treatment of Rupture of the Achilles Tendon: A Study of 20 Cases. J Foot Ankle Surg (Asia-Pacific) 2015;2(2):51-59.

Source of support: Nil

Conflict of interest: None

\section{INTRODUCTION}

Wound healing problems after the operative repair of a ruptured Achilles tendon has haunted surgeons for long. Despite various causative factors described, wound breakdown does occur in alarming frequency, compromising the end result. The surgical repair techniques are relatively simple, but wound healing

\footnotetext{
Consultant and Surgeon

Department of Orthopedics, Nirmala Memorial Hospital, Pune Maharashtra, India

Corresponding Author: Gautam D Salunkhe, Consultant and Surgeon, Department of Orthopedics, Nirmala Memorial Hospital, Pune, Maharashtra, India, Phone: 02026874587 e-mail: gdsalunkhe@gmail.com
}

remains unpredictable. Various modifications in the incisions, suture technique, augmentation and closure methods have not decreased the incidence of wound breakdown. Treatment of the wound is more cumbersome, extensive, time consuming and costly compared to the index surgery. When confronted with this problem, the pendulum of thought has swung away from surgical management toward conservative treatment. This has only resulted in the observation of re-ruptures on the conservative end of the spectrum.

\section{MATERIALS AND METHODS}

The percutaneous suture technique as described by Ma and Griffith ${ }^{1}$ to achieve approximation of the torn tendon was used in this study.

Twenty cases were studied from March 2004 to March 2012 (Table 1).

Twelve injuries were compound, inflicted by a sharp object like sickle in farming or industrial burr. Eight were simple, of which six were due to an unexpected misstep and two were sustained during sports (Fig. 1).

Table 1: Case details

\begin{tabular}{ll}
\hline Total cases & 20 \\
\hline Compound injury & 12 \\
Simple injury & 8 \\
Age range & $25-70$ years \\
Time of surgery: 1 week & 18 \\
$\quad 4$ weeks & 2 \\
\hline
\end{tabular}

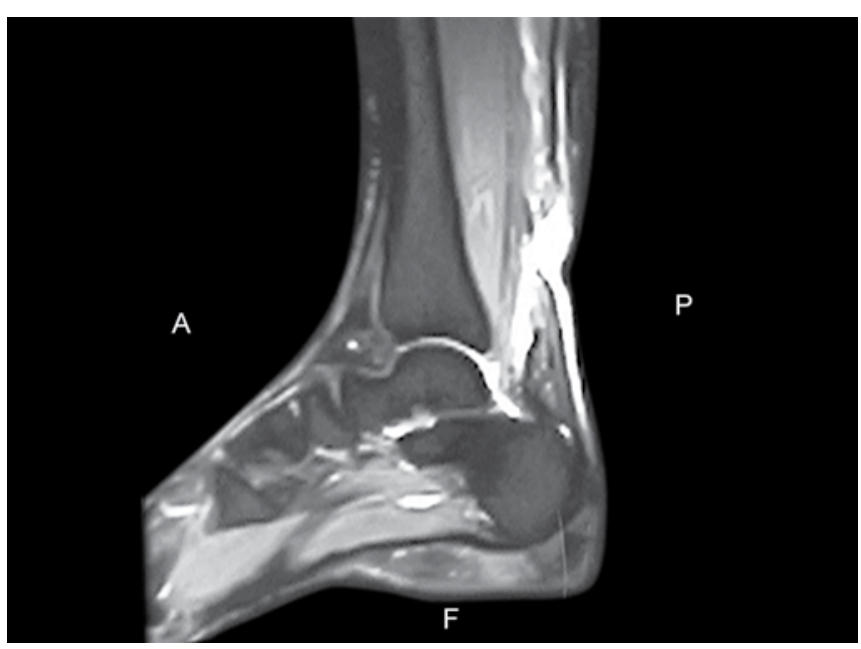

Fig. 1: Case 1: Magnetic resonance imaging of a 35-year-old sports woman sustaining a closed midsubstance rupture of Achilles tendon, during sports 

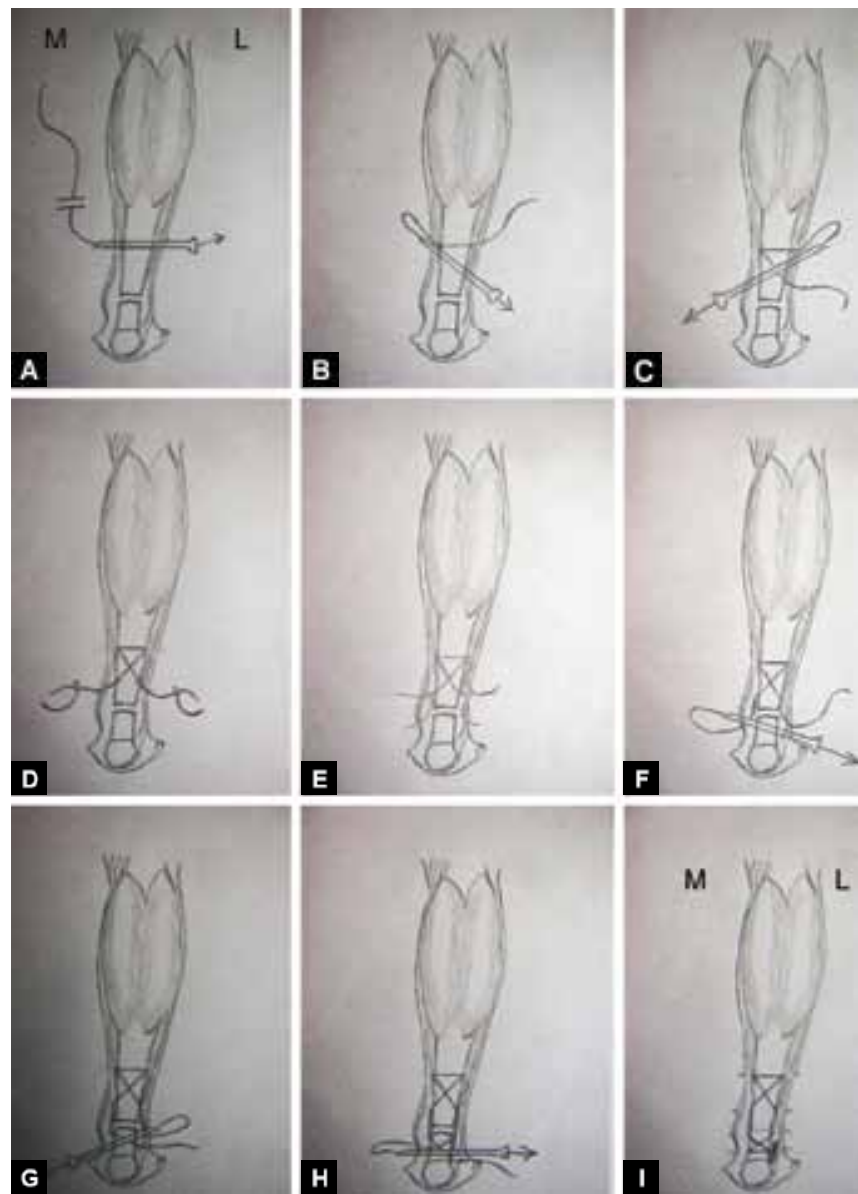

Figs 2A to I: Surgical technique: (A) Suture entry through spinal needle, transfixing proximal tendon, (B and C) oblique passage of suture ends, ( $D$ and $E$ ) sutures on curved needles, crossing rupture sites, $(F$ and $G$ ) oblique fixation of distal tendon, $(H)$ transfixation of distal tendon and (I) buried subcutaneous knot

Most injuries treated were fresh, and in the age group of 25 to 50 years of age. There were two cases treated late (at 4 weeks), both were in the age group 60 to 70 years.

Under spinal anesthesia and in prone position, a numbers 1 or 2 prolene or ethibond suture was introduced through stab incisions to transfix the proximal tendon. A numbers 16 or 18 spinal needle was used to pass the suture. After subcutaneous tunneling, the sutures were

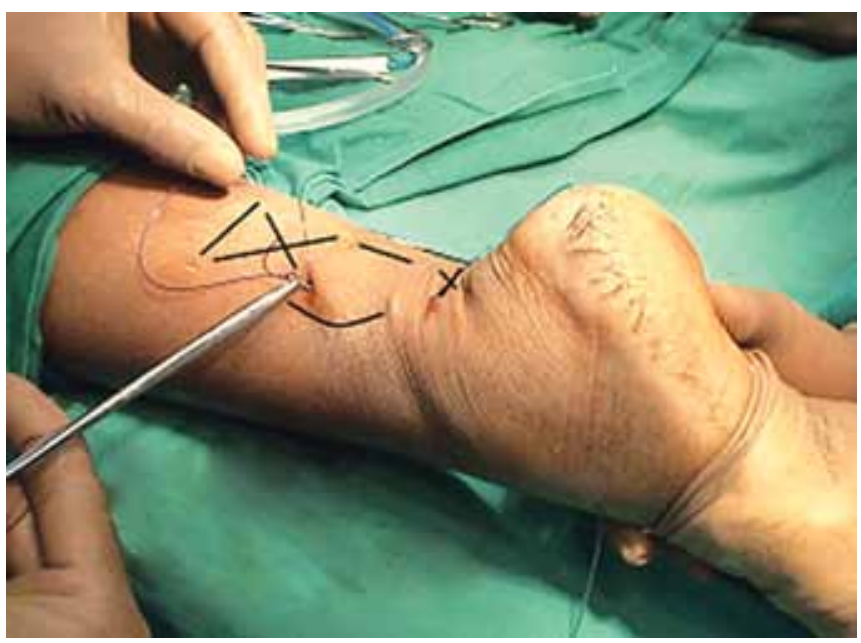

Fig. 3: Percutaneous surgery: Bold black lines show the path taken by the suture subcutaneously passed obliquely through the proximal tendon exiting at or near the proximal site of rupture, and out of the skin. The sutures were then passed subcutaneously under the skin to exit near the distal rupture, after which they were passed to transfix the distal tendon. The suture ends were then tied with the ankle in equinus and knee flexed, and the knot buried subcutaneously (Figs 2 to 4). The original wound, if present, was debrided and closed primarily. The operative time was 20 to 30 minutes. An above knee plaster cast was then applied, with the ankle in plantar flexion.

The cast was maintained in a non-weightbearing mode for 6 weeks. After first cast and suture removal, a below knee equinus cast was used in the weightbearing mode for 4 weeks. Later, the patients used a 1 inch heel raise for 4 weeks (total 14 weeks).

Active dorsiflexion was encouraged after that.

In the elderly, the time of immobilization in the first cast was extended by 2 weeks.

\section{Variations in Surgical Technique}

In compound injuries, the suture could be introduced in a bunnel stitch fashion, actually exiting and entering the ruptured tendon ends in the wound. 
In compound distal ruptures, the suture was passed through the calcaneum, and tied over a button over the heel. This suture was then removed after 6 weeks (Figs 6 to 9).

In bony avulsions, an additional stainless steel wire was used as a bone suture (Figs 11 and 12).

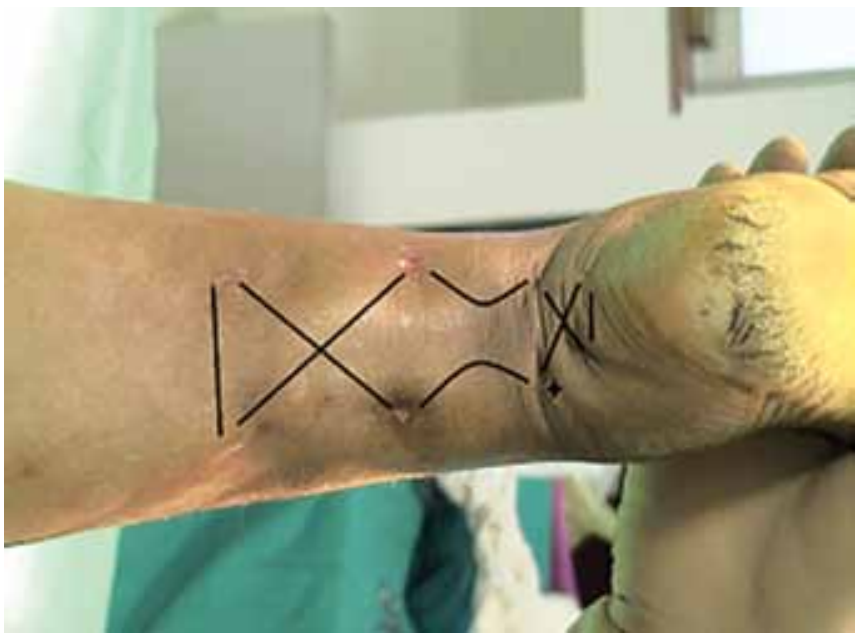

Fig. 4: Final path of suture and knot buried subcutaneously

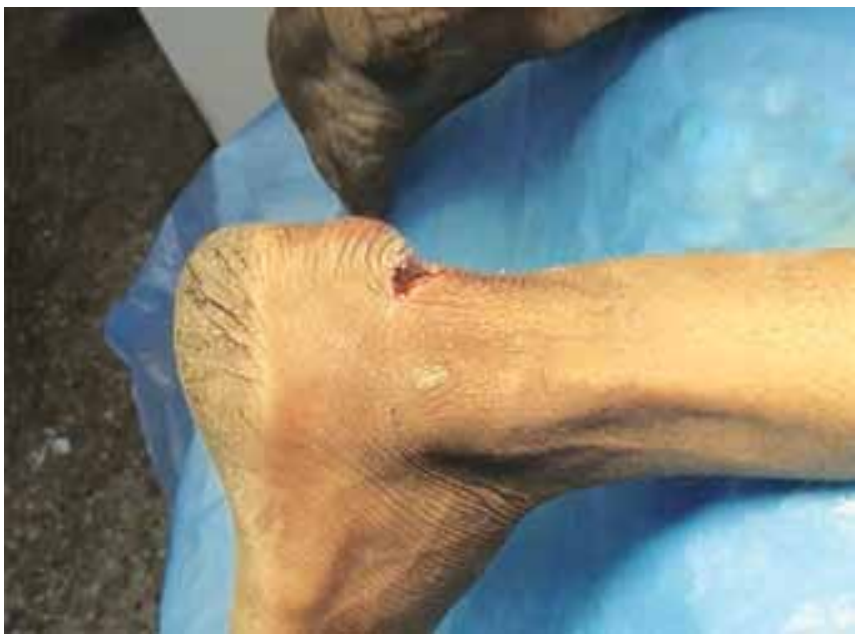

Fig. 6: Case 2: Open injury to Achilles tendon, near insertion

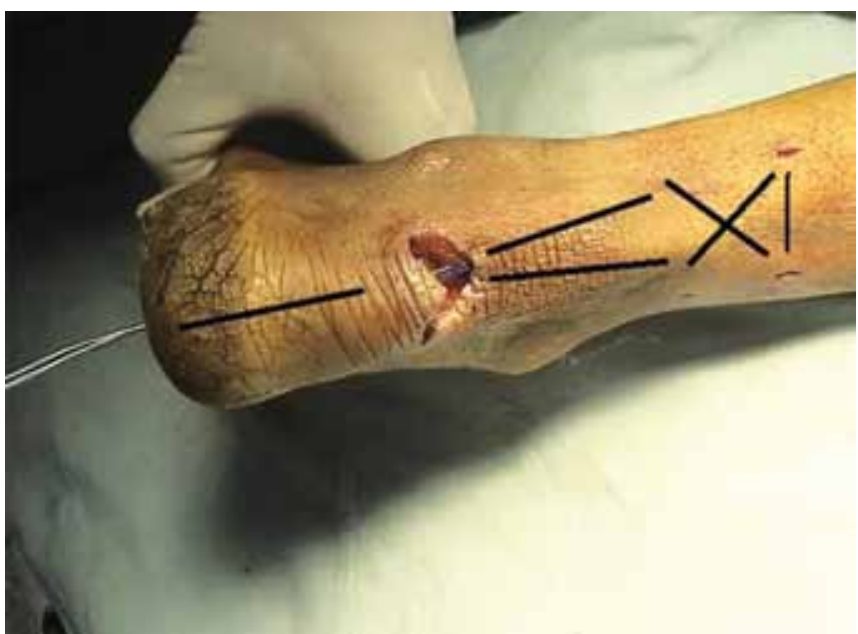

Fig. 8: Suture passed through the calcaneum
In injuries treated late, a transverse incision was taken at the rupture site. The suture was then introduced percutaneously in the proximal tendon, and then guided into the distal segment or calcaneum to complete the approximation (Figs 14 to 17). The transverse incision

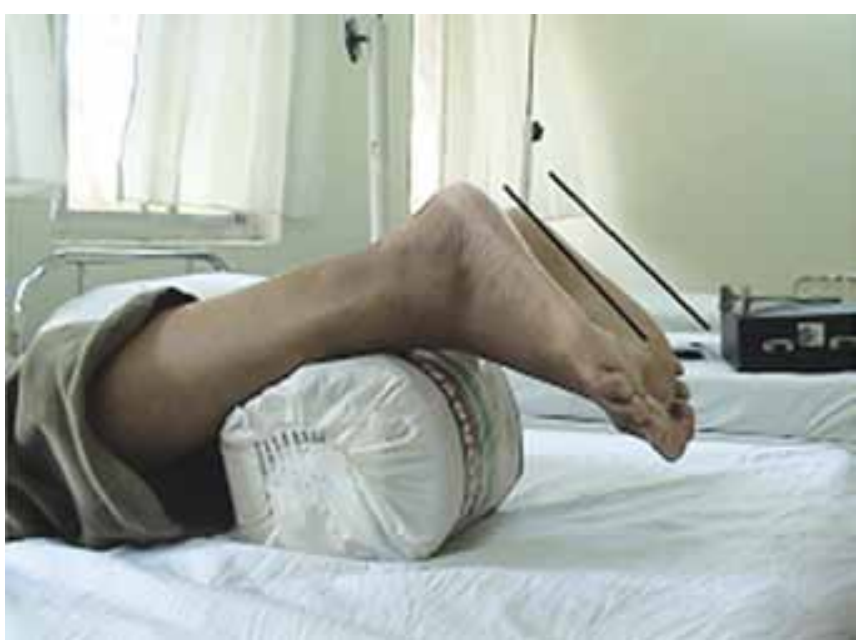

Fig. 5: Healing in normal tension after 12 weeks

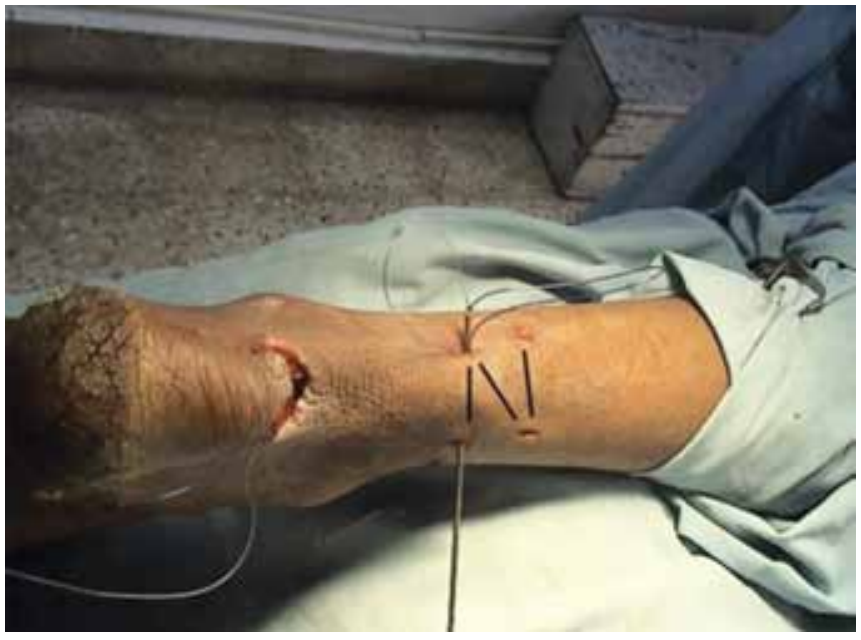

Fig. 7: Percutaneous repair through stab incisions. Path of subcutaneous suture marked in black lines

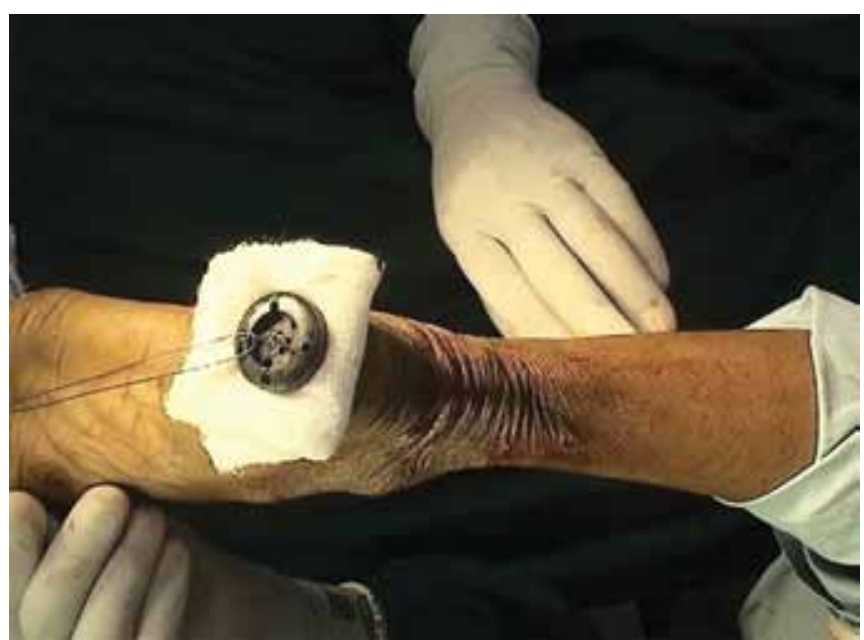

Fig. 9: Suture tied over a button on heel pad 
was then closed. In these instances, the operative time was 40 to 50 minutes.

\section{COMPLICATIONS}

There were no cases of infection (Table 2).

There was no incidence of wound dehiscence. It may be noted that all transverse wounds (compound injuries

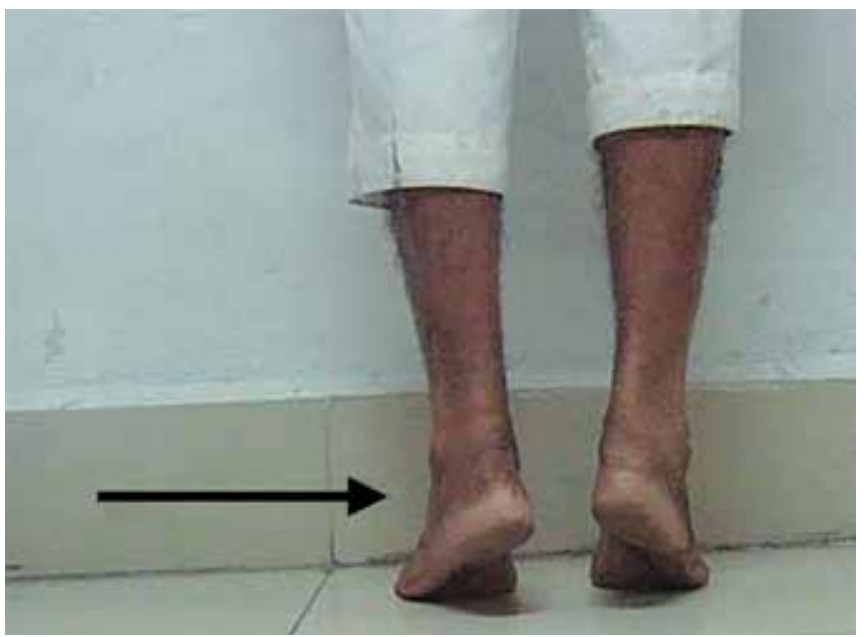

Fig. 10: End result—heel raise (arrow marking injured side)

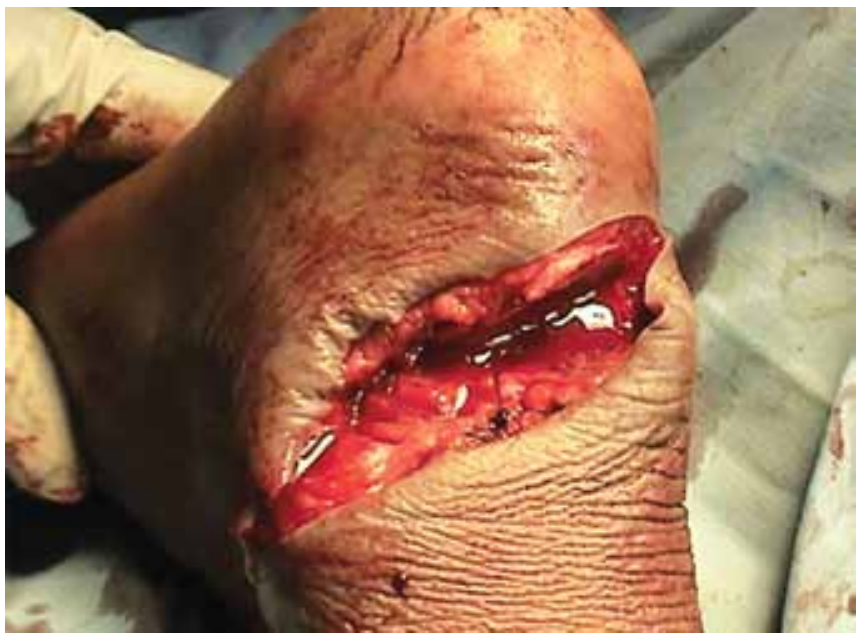

or surgical incisions) healed well in normal time (10-14 days).

There was some stiffness remaining in the knee and ankle when assessed after 4 months. This was reduced to negligible at 6 months.

There were no reports of deep vein thrombosis.

There were no cases of re-rupture seen up to a period of 2 years.

Sural nerve hypoesthesia was noted in two cases. This was noticed by the patients, though it did not bother them.

Table 2: Complications

\begin{tabular}{ll}
\hline & Percutaneous repair \\
\hline Delayed healing & 0 \\
Wound gape & 0 \\
Infection & 0 \\
Skin grafting & 0 \\
Venous thrombosis & 0 \\
Delayed final cast & 0 \\
Knee stiffness (at 4 months) & 1 \\
Ankle stiffness (at 4 months) & 2 \\
Ankle stiffness (at 6 months) & 0 \\
Sural nerve hypoesthesia & 2 \\
\hline
\end{tabular}
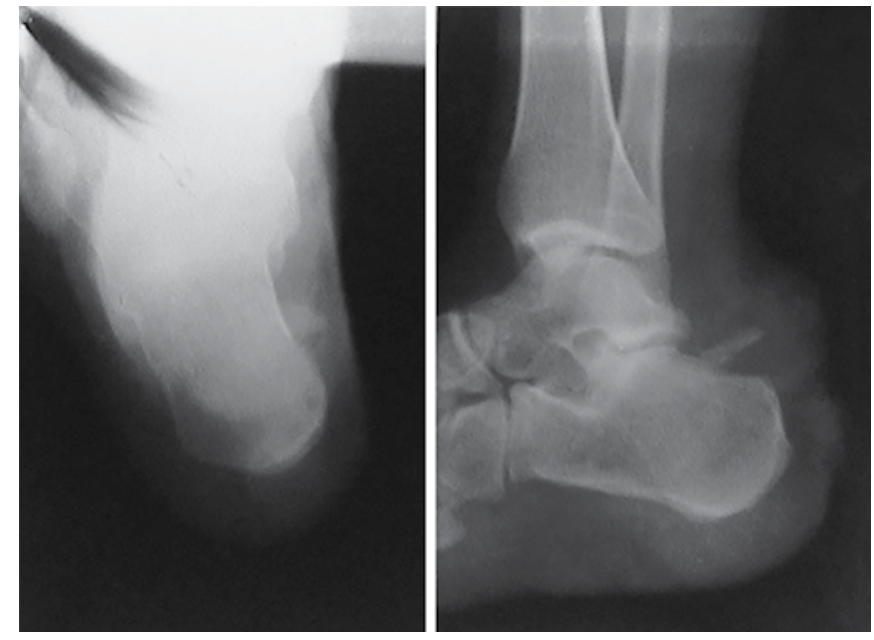

Fig. 11: Case 3: Open wound with slice of calcaneum avulsed with Achilles tendon
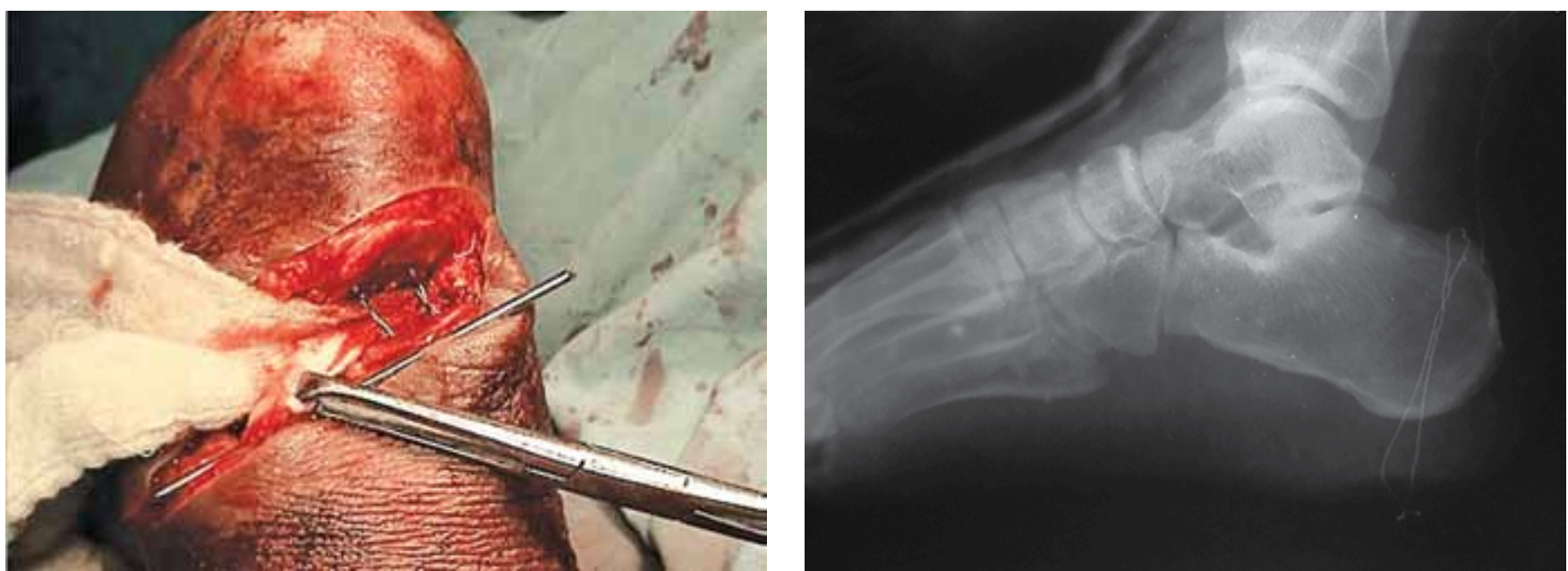

Fig. 12: Percutaneous repair with nonabsorbable suture in tendon and steel wire for bone 

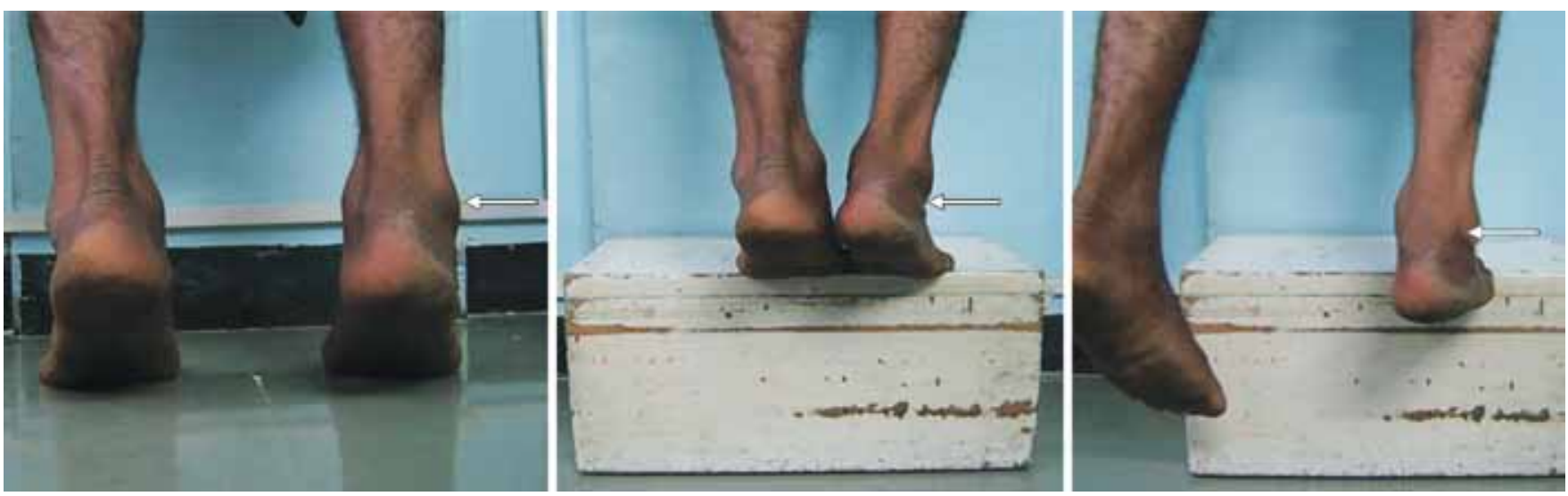

Fig. 13: End result: Heel raise, standing on edge, climbing on step edge (arrow marking injured side)

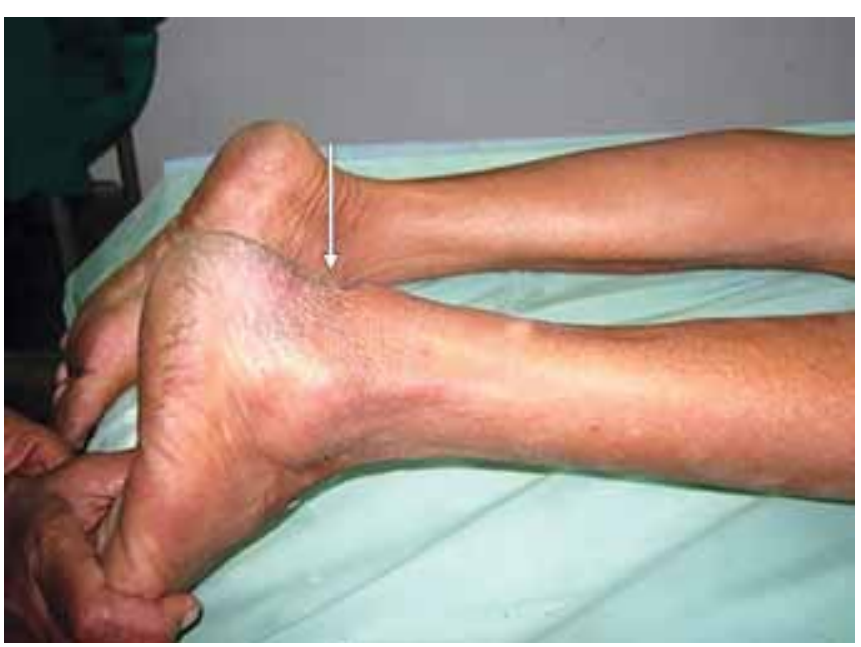

Fig. 14: Case 4: A 68-year-old patient, closed distal tear. Four weeks late presentation

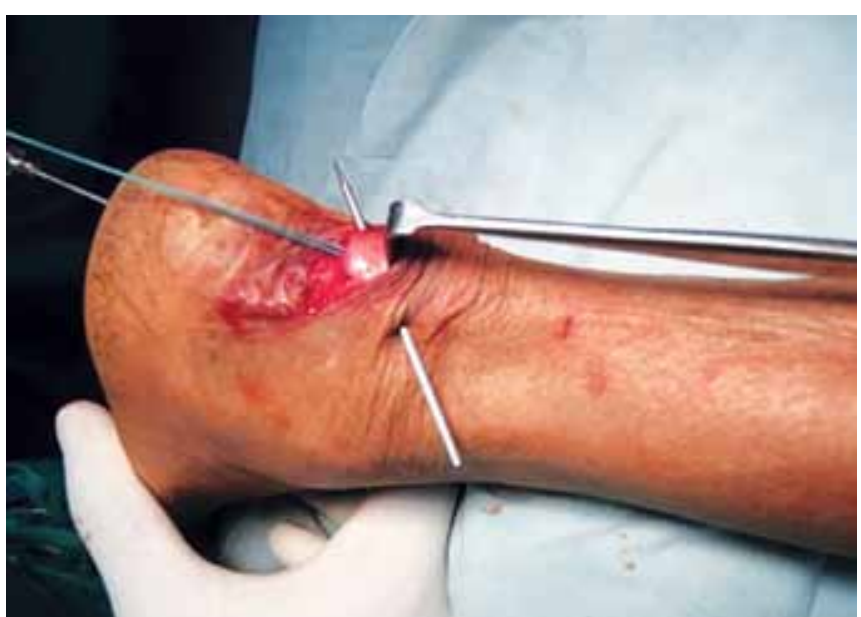

Fig. 16: Suture being passed into calcaneum and heel

Clinical recovery was seen after 9 months, at which time the patient was not even aware of the problem.

\section{RESULTS}

Percutaneous repair showed complete lack of wound healing problems. Transverse incisions taken for exposure of the rupture site never took a problem to heal. A minor problem regarding sural nerve injury was the only point of note.

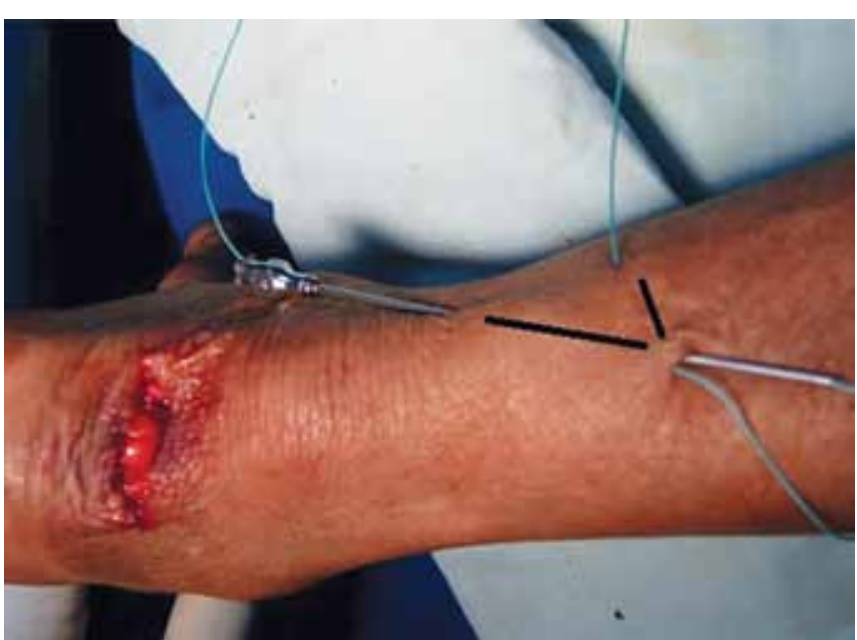

Fig. 15: Percutaneous repair with limited transverse incision

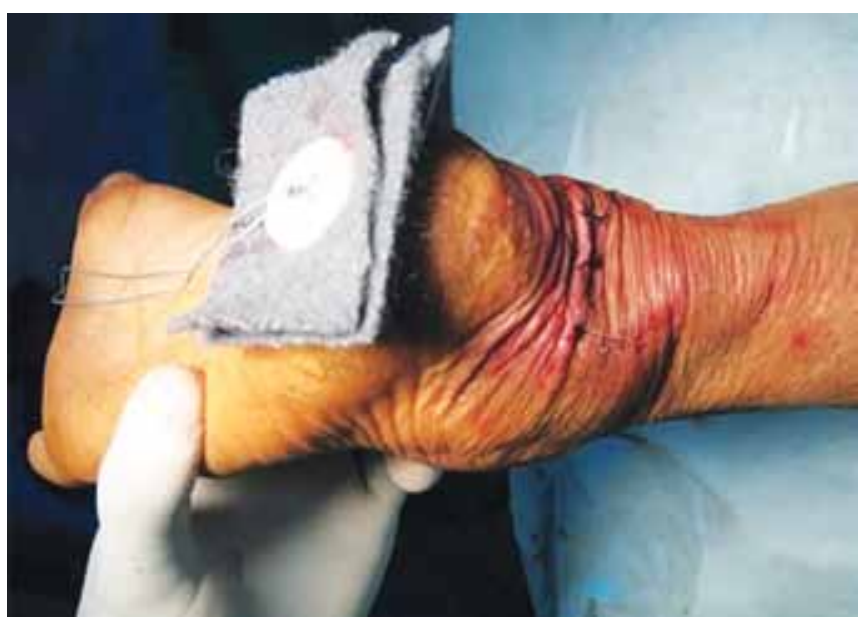

Fig. 17: Repair completed

There were no re-ruptures observed in this study. This was attributed to the immobilization schedule where the tendon is not stressed till it heals well.

Normal walking was achieved by 3.5 to 4 months, and return to strenuous and sports activity was achieved by 4 to 5 months. The tendons healed with a palpable thickening and were not adherent to the overlying skin after 4 months. 


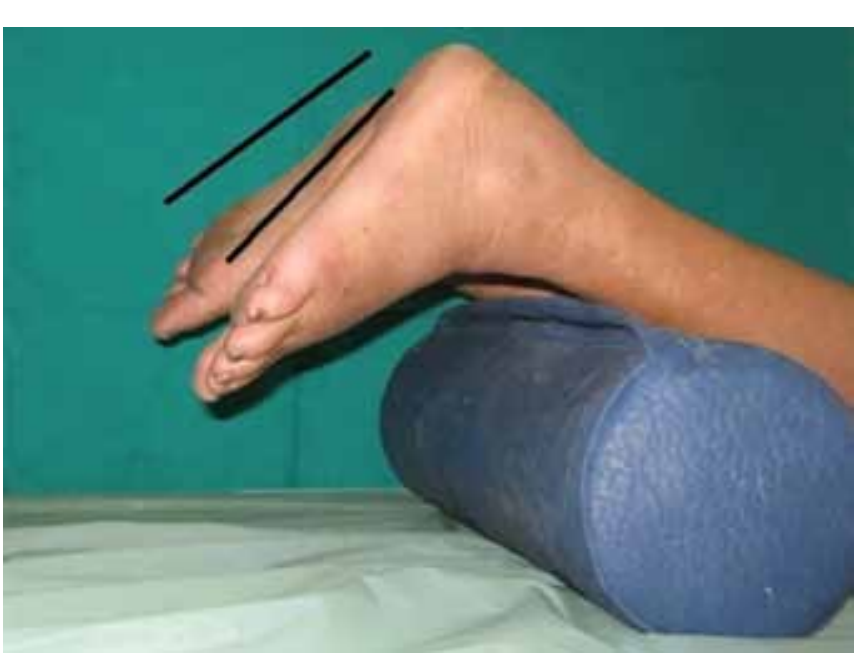

Fig. 18: Final healing in normal tension

The cosmetic result was most gratifying (Figs 5, 10, 13 and 18). A wholly percutaneous repair had miniscule scars; whereas when the rupture was exposed by a transverse incision, the scar was between 30 and $35 \mathrm{~mm}$, nonhypertrophic and along the lines of skin tension. This was not easily noticeable, and was highly appreciated by all patients (Table 3 ).

At the end of 6 months, all cases treated by percutaneous repair were showing excellent results, with greater comfort for the patient and surgeon alike.

The final result was assessed at 4, 6 and 12 months using the Leppilahti scores (Table 4). This method was simple, easy to execute and interpret. Isokinetic muscle strength was not tested for logistic and financial reasons, which was done by the repeated single heel raise test.

Percutaneous repair had 75\% excellent and 20\% good results (Table 5). The one fair result was in an elderly patient treated late, which took longer time to heal. There was no poor result.

Follow-up was done up to 2 years.

\section{DISCUSSION}

\section{Surgical Technique}

Compound injuries always have a transverse cut; this wound never gave a healing problem (Figs 10 and 13).

Table 3: Other parameters

\begin{tabular}{ll}
\hline Other parameters & Percutaneous repair \\
\hline Return to work (average) & $12-14$ wks (mean 13) \\
Return to work (strenuous/sports) & $15-18$ wks (mean 16.5) \\
Scar length & $0-3.5 \mathrm{~cm}$ transverse \\
Cosmesis (patient's opinion) & \\
Excellent & 14 \\
Good & 6 \\
Fair & 0 \\
Poor & 0 \\
\hline
\end{tabular}

Similarly, a transverse incision along the Langer's lines always healed beautifully (Fig. 18). A longitudinal incision, whether midline, paramedian or curved, always runs a high and unpredictable risk. It was avoided altogether. Transverse incisions, three in number, were advocated by Young et $\mathrm{al}^{2}$ Webb and Bannister ${ }^{3}$ and Guilo et $\mathrm{al}^{4}$

Table 4: Leppilahti score

\begin{tabular}{|c|c|c|}
\hline Clinical & Factors & $\begin{array}{l}\text { Score } \\
\text { (pts) }\end{array}$ \\
\hline \multirow[t]{4}{*}{ Pain } & None & 15 \\
\hline & $\begin{array}{l}\text { Mild: no limitation on } \\
\text { recreational activity }\end{array}$ & 10 \\
\hline & $\begin{array}{l}\text { Moderate: limitation on } \\
\text { recreational, but not } \\
\text { daily activity }\end{array}$ & 5 \\
\hline & $\begin{array}{l}\text { Severe: limitation on } \\
\text { recreational and daily activity }\end{array}$ & 0 \\
\hline \multirow[t]{4}{*}{ Stiffness } & None & 15 \\
\hline & $\begin{array}{l}\text { Mild: no limitation on } \\
\text { recreational activity }\end{array}$ & 10 \\
\hline & $\begin{array}{l}\text { Moderate: limitation on } \\
\text { recreational, but not daily } \\
\text { activity }\end{array}$ & 5 \\
\hline & $\begin{array}{l}\text { Severe: limitation on } \\
\text { recreational and } \\
\text { daily activity }\end{array}$ & 0 \\
\hline \multirow[t]{4}{*}{ Calf muscle weakness } & None & 15 \\
\hline & $\begin{array}{l}\text { Mild: no limitation on } \\
\text { recreational activity }\end{array}$ & 10 \\
\hline & $\begin{array}{l}\text { Moderate: limitation on } \\
\text { recreational, but not daily } \\
\text { activity }\end{array}$ & 5 \\
\hline & $\begin{array}{l}\text { Severe: limitation on } \\
\text { recreational and daily activity }\end{array}$ & 0 \\
\hline \multirow[t]{3}{*}{ Footwear restrictions } & None & 10 \\
\hline & Mild: most shoes tolerated & 5 \\
\hline & $\begin{array}{l}\text { Moderate: modified shoes } \\
\text { tolerated, not fashionable shoes }\end{array}$ & 0 \\
\hline \multirow{4}{*}{$\begin{array}{l}\text { Active ROM difference } \\
\text { between ankles }\end{array}$} & Normal $\left(<6^{\circ}\right)$ & 15 \\
\hline & Mild $\left(6-10^{\circ}\right)$ & 10 \\
\hline & Moderate $\left(11-15^{\circ}\right)$ & 5 \\
\hline & Severe $\left(>15^{\circ}\right)$ & 0 \\
\hline \multirow[t]{4}{*}{ Subjective result } & Very satisfied & 15 \\
\hline & Satisfied: minor reservations & 10 \\
\hline & Satisfied: major reservations & 5 \\
\hline & Dissatisfied & 0 \\
\hline Isokinetic muscle & Excellent & 15 \\
\hline \multirow[t]{3}{*}{ strength } & Good & 10 \\
\hline & Fair & 5 \\
\hline & Poor & 0 \\
\hline
\end{tabular}

Table 5: Results

\begin{tabular}{ll}
\hline Leppilahti score & Percutaneous \\
\hline Excellent (100-90) & $15(75 \%)$ \\
Good (85-75) & $4(20 \%)$ \\
Fair $(70-60)$ & $1(5 \%)$ \\
Poor $(<55)$ & $0(0 \%)$ \\
\hline
\end{tabular}


for a Achilles tendon repair. During the surgery, a transverse incision was taken over the rupture site, if required. In cases where wound healing was suspect, a small window was cut in the plaster over the transverse incision to inspect the wound. In later stages of the study, the window was avoided as wound healing was consistently good.

The suture material used was number 2 ethibond. This is useful in midsubstance tears, where bony tunneling is not involved. The knot is barely palpable when buried, unlike prolene. ${ }^{1,5}$ Its disadvantage is that it loses stiffness when moistened in soft tissues, making it slightly difficult to pass in later stages of surgery. When tunneling through the calcaneum is needed, prolene is preferred. This material maintains stiffness throughout the procedure, and is easy to pass through the bony tunnel. Its knot makes a firm mass of size, but this is tied outside the skin of the heel over a button. At cast removal, the knot is cut out, and the sutures retract inside the tunnel, rendering them nonpalpable.

Many authors have noted the complications caused by poor wound healing in the surgical repairs of the ruptured Achilles tendon. Furthermore, attempts at early mobilization have been associated in an increasing rerupture rate ${ }^{5-9}$ Kangas et $\mathrm{al}^{10}$ noted that there was a role of early mobilization in motivated and athletic patients, but advised immobilization for others. This suggests that the control on mobilization has a key role to promote healing and avoid re-ruptures; early mobilization is not the rule for all patients. Such a trial was avoided in this study, and all patients were immobilized in a cast for the first 6 weeks to ensure initial healing.

There has been a recommendation that a below knee cast is sufficient for surgical repairs. In literature, however, whenever the case of re-rupture is discussed, it is attributed to unsupervised immediate mobilization, absence of proper orthosis, inadequate opposition, unfortunate accidents ${ }^{8}$ and because the below knee cast did not hold the ruptured ends together when traction forces are applied across the knee. ${ }^{1}$ In terms of recovery of strength, the time period may take up to 1 year. ${ }^{11}$ In a study done at multiple centers, some surgeons did have a personal preference for the above knee cast. ${ }^{9}$ In the present study, it was observed that, with the knee in extension and mild plantar flexion, the approximation of tendon ends is neither easy to achieve nor tension-free on table. It was felt too much to expect it to remain so when the patient was active thereafter. This made the result prone to re-rupture. Hence, the above knee cast was used to neutralize the gastrocnemius. The knee and ankle joints are uninjured, and immobilizing uninjured joints did not result in unrecoverable stiffness. The haste to reduce the extent and time of immobilization seems to be driven by the demand to reduce external support and promote accelerated healing by early functional mobilization and weightbearing at all costs. ${ }^{12}$ In this study, difficulty in repeated and closely supervised follow-up, accompanied by suspect patient compliance made such a protocol felt to be risky. Though functional postoperative treatment has showed no difference in the incidence of re-ruptures ${ }^{13}$ immobilization was used in this study and no re-ruptures were observed.

The Cochrane database systems review ${ }^{14}$ has noted that open repairs have a significantly higher risk of complications, which may be reduced by conducting the surgery percutaneously. They also note that adequate splintage may reduce the overall complication rate.

\section{Ultrasound and Magnetic Resonance Imaging}

The role of investigations for diagnosis and assessment of healing has been studied by serial ultrasounds by Majewski et al. ${ }^{15}$ These were done at 4, 8, 12, 26 weeks and 2.5 years. They found maximum healing at 26 weeks on ultrasound. Cretnik et $\mathrm{al}^{16}$ has found that a diastasis of $0.5 \mathrm{~mm}$ on ultrasound intraoperatively as acceptable for healing magnetic resonance imaging (MRI) provides a more accurate assessment. A similar serial study by Fujikawa et $\mathrm{al}^{17}$ using MRI at 4, 8, and 12 weeks showed a gap of $100 \%$ at 4 weeks, $80 \%$ at 8 weeks, and $0 \%$ at 12 weeks in percutaneous repair; normal tendon contour at 30,90 and $100 \%$ at the same time scale. In their comparison between open and percutaneous repair, they note that although on MRI there is a lesser gap at 4 weeks (open repair $6-30 \mathrm{~mm}$ to percutaneous repair 6-48 mm), there is no gap in either group at 12 weeks. These gap sizes, suggest that normal healing does take a minimum of 12 weeks. Their immobilization protocol began with an equinus cast, which was changed serially to lesser angles after 2 weeks till removal at 7 weeks. A point to note is that they have excluded cases which developed re-rupture during the study. This happened at 7 to 8 weeks in four out of 40 cases treated percutaneously. This suggests that proper initial immobilization would help to prevent re-ruptures. In this study, proper initial immobilization and its gradual withdrawal was kept to match this time scale.

Cost constraints and patient noncooperation prevented routine serial MRI assessment. Also, the concept of frequent changes of casts and joint positions was felt to be risky. Ultrasound examination was done in few willing cases at the end of 16 weeks, which showed satisfactory healing. Real time intraoperative ${ }^{16}$ and postoperative ultrasound examination ${ }^{18}$ has not been done in any case. 


\section{Cost Effectiveness}

Carmont et $\mathrm{al}^{19}$ have noted that percutaneous repair required half the cost than that of open surgery, while giving a comparable results and complication rates.

Various needles and sutures have been used (Tenolig, lengemann wires, harpoon wires, anchors, fibrin glue $)^{8,20}$. Also, postoperative braces and boots have been developed. This adds to the costs and complications of the procedure.

Sutures materials, spinal needles and coat buttons which were cheap and readily available were used for this study.

\section{Comparison of Open to Percutaneous Repair}

There are many publications referring to why percutaneous repair was more preferable. ${ }^{5,6,9,21-24}$ These compare muscle strength, range of movement, calf and ankle perimeters, single heel raise test, time of return to work, re-rupture incidence and cosmesis.

\section{Casting and Percutaneous Repair}

Primarily to avoid complications, casting alone has been recommended. ${ }^{25}$ The time for absolute casting here was 8 weeks, followed by a supervised rehabilitation program. This has a higher re-rupture rate.

Percutaneous repair combined the advantages of approximation of the tendon without the disadvantages of a formal incision. Serial observation and ultrasound examination was avoided. By avoiding undue haste to mobilize early, re-ruptures were prevented.

\section{Re-rupture and Augmentation}

Gorschewsky et $\mathrm{al}^{8}$ noted that they had one case in 66 had a re-rupture and an unsatisfactory result. The postoperative protocol involved below knee cast till 3 weeks, followed by cast and suture removal, and full weightbearing, with active dorsiflexion beginning at 6 weeks. They note that the patient is not wearing a plaster from the 3 week, which gave rise to a certain danger for re-rupture. Similar observations of hasty mobilization, improper orthosis and accidents are echoed in all instances of re-rupture. Hence, proper cast immobilization was used for 6 weeks; and no re-ruptures were observed.

Kangas et $\mathrm{al}{ }^{10}$ have noted that there was no advantage of augmentation procedures.

Re-rupture after augmentation and repair has been reported 54 to 80 days after the primary surgery. ${ }^{26}$ This was attributed to subtotal closure of paratenon, bulk of augmentation, and inadequate immobilization.

No augmentation was done in this study.

\section{SAFETY}

The main constant complication reported is sural nerve injury. Two such occurrences were noticed in this study. This, however, was of a minor nature and not of much consequence to the patient. Recovery has been noticed till 10 months. Majewski et $\mathrm{al}^{27}$ have enlarged the proximal lateral incisions to isolate and retract the nerve while conducting a minimal incision surgery.

The other reported complication is of venous thrombosis. No such complication was seen.

Materials and hardware did give an incidence of breakages and failures, as did immediate weightbearing without proper immobilization. ${ }^{28}$ Hence, simple percutaneous repair with immobilization were felt more safe and reliable.

\section{CONCLUSION}

Percutaneous repair, as advocated by Ma and Griffith in 1977, is a simple, easy, safe and cost-effective technique for the repair of the Achilles tendon rupture. It has extremely few and minor complications. An uncompromised period of immobilization and rehabilitation prevents incidence of re-ruptures and stiffness. Cosmesis, return to activity, patient satisfaction, and long-term results are most gratifying. The percutaneous technique is recommended over open repair or conservative casting.

\section{ACKNOWLEDGMENTS}

I sincerely acknowledge the assistance rendered by Dr Ashok Shyam for the research required for the study of this article. I thank Dr Kiran Kharat and Dr Sampat Dumbre-Patil for the guidance and help provided in the writing of this article.

\section{REFERENCES}

1. Ma GWC, Griffith TG. Percutaneous repair of acute closed ruptured Achilles tendon. Clin Orthop Rel Res 1977 Oct; 128:247-255.

2. Young J, Sayana MK, Maffulli N. Percutaneous repair of acute rupture of the achilles tendon. Minimally invasive surgery in orthopedics. Springer Science, Business Media LLC; 2010. Chap 40, 335-364.

3. Webb JM, Bannister GC. Percutaneous repair of the ruptures Achilles tendon. JBJS Br 1999;81-B5:877-880.

4. Guilo S, Del Buono A, Dias M, Denaro V, Maffulli N. Percutaneous repair of Achilles tendon. Surgeon II 2013;14-19.

5. Haji A, Sahi A, Symes A, Vyas JK. Percutaneous versus open Achilles tendon repair. Foot ankle Int 2004 Apr;25(4):215-218.

6. Bradley JP, Tibone JE. Percutaneous and open surgical repairs of achilles tendon ruptures: a comparative study. Am J Sports Med 1990;18(2):188-195.

7. Carmont MR, Silbernagel KG, Edge A, Mei-Dan O, Karlsson J, Maffulli N. Functional outcome of percutaneous achilles 
repair. Orthop J Sports Med 2013 Jan-Jun. Available at: http:// ojs.sagepub.com/content/1/1/232596711//3494584.

8. Gorschewsky O, Pitzl M, Putz A, Klakow A, Neumann W. Percutaneous repair of acute achilles tendon rupture. Foot Ankle Int 2004 Apr;25(4):219-224.

9. Lim J, Dalai R, Waseem M. Percutaneous vs open repair of the ruptured achilles tendon: a prospective randomized controlled study: Foot Ankle Int 2001;22(7):559-565.

10. Kangas J, Pajala A, Siira P, Hamalainen M, Leppilahti J. Early functional treatment versus early immobilization in tension of the musculo-tendinous unit after achilles rupture repair. J Trauma 2003 Jun;54(6):1171-1180.

11. Kou J. AAOS clinical practice guideline: acute achilles tendon rupture: J Am Acad Orthop Surg 2010;18(8):511-513.

12. Brumann M, Baumbach SF, Mutschler W, Polzer H. Accelerated rehabilitation following achilles tendon repair after acute rupture. J Injury 2014;45(11):1782-1790.

13. Buchgraber A, Passler HH. Percutaneous repair of achilles tendon rupture. Immobilization versus functional postoperative treatment. Clin Orthop Rel Res 1997;341: 113-122.

14. Khan RJ, Carey Smith RL. Surgical interventions for treating acute achilles tendon ruptures. Cochrane Database Syst Rev 2010 Sep 8;9(CD 003674).

15. Majewski M, Lehmann M, Dick W, Steinbruck K. Value of sonography to monitor the course of achilles tendon rup-ture after treatment. Unfallchirurg 2003 Jul;106(7): 556-560.

16. Cretnik A, Kosanovic M, Smrkolj V. Percutaneous versus open repair of the ruptured achilles tendon. Am J Sports Med 2005;33(9):1369-1379.

17. Fujikawa A, Kyoto Y, Kawaguchi M, Naoi Y, Ukegawa Y. Achilles tendon after percutaneous surgical repair: serial MRI observation of uncomplicated healing. Am J Roentegen 2007 Nov;189(5):1169-1174.
18. Blankenstein A, Israeli A, Dudkiewicz I, Chechik A, Ganel A. Percutaneous achilles tendon repair combined with real-time sonography. Isr Med Assoc J 2007 Feb;9(2):83-85.

19. Carmont MR, Heaver C, Pradhan A, Mei-Dan O, Gravare Silbernagel K. The cost effectiveness of open versus percutaneous repair. Knee Surg Sports Traumatol Arthrosc 2013 Jun;21(6):1361-1368.

20. Taglialavoro G, Biz C, Mastrangelo G. The repair of the achilles tendon rupture: comparison of two percutaneous techniques. Strat Traum Limb Recon 2011;6:147-154.

21. Goren $D$, Ayalon $M$, Nyska M. Isokinetic strength and endurance after percutaneous and open surgical repair of achilles tendon ruptures. Foot Ankle Int 2005;26(4):286-290.

22. Henriquez H, Munoz R, Carcuro G, Bastias C. Is percutaneous repair better than open repair in acute achilles tendon rupture? Clin Orthop Rel Res 2012 Apr;470(4):988-1003.

23. Klein EE, Lowell W, Baker JR, Scott W, Sung W, Knight J. Retrospective analysis of mini-open versus open repair for acute achilles tendon ruptures. Foot Ankle Spec 2013;8(1): 15-20.

24. McMahon SE, Smith TO, Hing CB. A meta-analysis of randomised controlled trials comparing conventional to minimally invasive approaches for repair of an achilles tendon rupture. Foot Ankle Surg 2011;17:211-217.

25. Fierro NL, Sallis RE. Achilles tendon rupture. Is casting enough? Postgrad Med 1995 Sep;98(30):145-152.

26. Garcia-German D, Rubio-Quevedo R, Lopez-Goenaga J. Achilles tendon recurrent rupture following surgical repair. Foot ankle Surg 2009;15(3):152-154.

27. Majewski M, Rohrbach M, Czaja S, Oschner P. Avoiding sural nerve injuries during percutaneous achilles tendon repair. Am J Sports Med 2006;34(5):793-798.

28. Maes R, Copin G, Averous C. Is percutaneous repair of the achilles tendon a safe technique? Acta Orthop Belg 2006 Apr; 72(2):179-183. 